\title{
Multi-Period Optimization with Loss-Adverse Customer Behavior: Joint Pricing and Inventory Decisions with Stochastic Demand
}

\author{
Hongfang Song \\ School of Management and Economics, Beijing Institute of Technology, Beijing 100081, China \\ songhongfang2007@gmail.com
}

Lun Ran *

School of Management and Economics, Beijing Institute of Technology, Beijing 100081, China ranlun@bit.edu.cn

Jennifer Shang

School of Business Administration, Southwestern University of Finance and Economics, Chengdu 610074, China

Katz Graduate School of Business, University of Pittsburgh, Pittsburgh PA 15260, USA

shang@ katz.pitt.edu

\begin{abstract}
To maximize a firm's profit over a finite planning horizon, we develop a dynamic optimization model by considering loss aversion when making pricing and inventory decisions. We estimate customer demand through a choice model, which incorporates reference price, utility function, and customer loss aversion. Our model forms the core of the expert system for decision support. Through a sequence of Bellman equations, we find that the firm's profit is a concave function of price and inventory, and we solve the model optimally. The profit is positively correlated with the reference price, and the price and inventory decisions are non-monotonic functions of loss aversion intensity. Our results shed new light on pricing and inventory management with customer behavior in a multi-period system. Through various theorem developments, we are able to identify the optimal inventory level and the corresponding price. Numerical examples are provided to illustrate and validate the model and to derive managerial insights. To show the potential significance, we demonstrate how a dynamic programming model yields good results with customer loss aversion under realistic customer behavior assumptions. Our system can improve the efficiency of decision making and provide better customer service.
\end{abstract}

Keywords: Loss aversion; Dynamic pricing; Inventory control; Uncertain demand

\section{Introduction}

To make better operations decisions and to run a successful marketing campaign, one must take customer behavior (e.g., perception, decision making processes, beliefs) into consideration. Customer behavior plays an important role in pricing decisions and 
it can help retailers to develop successful business strategies. In this research, we focus on customers' loss-averse behavior. Loss-averse customers carefully evaluate the difference between the reference price and the actual price when making purchasing decisions. An unfavorable current price is often regarded as a loss, which significantly reduces customers purchase propensity and hinders retail sales (Popescu $\& \mathrm{Wu}, 2007)$.

From the operations perspective, we find that customers' purchasing decisions are indirectly affected by inventory level, as inventory level influences price and price affects sales. For example, sales of existing U.S. homes decreased significantly in January 2015 due to lack of houses available on the market, despite buoyant market and abundant customers. With diminishing supply, the price of preowned properties increased by 6.2 percent from a year ago (Mutikani, 2015). High price that causes customers' aversion has sidelined potential buyers from the market, which suggests that low inventories have a negative impact on sales. This shows that inventory level does influence product price, sales and overall market performance.

Loss aversion is a pervasive behavior, and the reference price often serves as an important element influencing customers' perception of the value of a product (Giorgi \& Post, 2011). The reference price is exogenous and is defined as the price that customers expect or deem fair to pay. The extent of loss or gain a customer senses is determined by the difference between the reference price and the actual price (Mazumdar et al., 2005). Firms have long recognized that customers' willingness to purchase a product is closely related to its reference price. When the reference price is higher than the current price, customers appreciate the surplus utility, thus increasing the likelihood of purchase, as the product becomes more attractive. To lure customers, firms may attempt to inflate the original price to raise customers' reference price; such a skimming strategy is often employed to manage customers' expectation (Nasiry \& Popescu, 2011). Due to the significance of reference price on customers' loss-averse behavior, we examine the relationship between customer loss aversion and marketing decisions (pricing) and the firm's operation decisions (inventory level).

The literature on joint pricing and inventory management abounds, e.g. 
Federgruen and Heching (1999), Chen and Simchi-Levi (2004), Güler et al. (2014). This is a topic under the domain of expert system and intelligent management systems. The expert system we proposed is for multi-period planning horizon, which uses dynamic programming to identify optimal pricing and inventory level. It takes into account consumer loss aversion by incorporating consumer psychology in demand estimation. The expert system is practical and easy to implement.

The organization of this paper is as follows: In Section 2, we review the relevant literature. Section 3 develops the demand function, optimizes the retail price and inventory level, and examines the relationship between customers' loss-averse behavior and expected profit. Numerical studies are conducted in Section 4 to understand the impacts of price, inventory, and loss aversion on profit and demand. Section 5 provides concluding remarks and suggests future research directions.

\section{Literature Review}

\subsection{Loss Aversion}

Since the introduction of prospect theory (PT) by Kahneman and Tversky (1979), many researchers have analyzed human behavior and shown that decision-makers are not rational and do not conform to expected utility function. Loss aversion is associated with customers' perceived risk, which is an essential part of utility theory. Tversky and Kahneman (1991) confirm that loss aversion does exist, and a reference-dependent model can be established based on utility theory. They find that a utility function is concave for gains and convex for losses, and the loss aversion utility is S-shaped. Indeed, loss aversion is a widespread phenomenon that has important implications for many scientific disciplines. Many abnormal fluctuations can be understood by the concept of loss aversion. As the learning continues, the value of the gain or loss perceived by customers changes continuously. Tversky and Kahneman (1992) believe that customers associate a product's value with their experience (such as past price). If the perceived value of a product is lower than the price, customers will not purchase the product. The specific form of the utility function is: 


$$
v(x)=\left\{\begin{array}{c}
x^{\alpha}, i f x \geq 0 \\
-\lambda(-x)^{\beta}, i f x<0
\end{array} .\right.
$$

where a typical value of $\lambda$ is 2.25 (Tversky \& Kahneman, 1992). Hardie et al. (1993) develop a reference-dependent choice model using the Multinomial Logit model to estimate the probabilities of customer purchase. Barberis and Huang (2001) employ a utility function to measure the degree of loss aversion and find that price is significantly affected by the degree of customers' loss aversion.

Alternatively, Thaler et al. (1997) measure the degree of aversion by comparing the selling price with the reference price and conclude that the pain of loss is much more intense than the gain of pleasure. Similarly, Ho and Zhang (2008) examine a reference-dependent newsvendor model on a multilocation inventory system in a laboratory setting.

Ho et al. (2010) show that decision-makers are loss-averse, and stockouts hurt profits, which is also supported by Schweitzer and Cachon (2000). Furthermore, Pope and Schweitzer (2011) present that loss aversion exists in a highly competitive market and that even experienced decision-makers display loss-averse behavior and make bad decisions. Nasiry and Popescu (2011) find that both peak-end anchoring and loss aversion behaviors limit the benefits of varying prices and caution about the negative effects of deep discounts on profits. Finally, Kuksov and Wang (2014) discover that customers' loss-averse behavior may result in higher prices and profits when their reference price is relatively high compared to search costs.

\subsection{Pricing and Inventory Decision - Multi-Period Decisions}

Schwartz (1970) and Wagner and Whitin (1958) proved that optimal prices may be different at different time periods and independent of each other. Petruzzi and Dada (1999) propose optimal pricing and inventory models for both deterministic and stochastic demand. Federgruen and Heching (1999) develop dynamic pricing and inventory control models for multiple periods and identify optimal dynamic pricing and inventory policies. They find that base-stock (order-up-to) policy is optimal; the optimal price is associated with inventory level; and dynamic pricing may bring 
significant profits in a stationary environment. In addition, Federgruen and Heching (2002) present an approximate dynamic programming to derive an optimal pricing and inventory policy. Liu and Chen (2011) analyze a heuristic method for the inventory and pricing problem.

Chen and Simchi-Levi (2004a) show that the profit function is k-concave given a fixed ordering cost. However, the profit function may not be k-concave if the demand process is multiplicative, and an (s, S) policy may fail to be optimal. In contrast, Biller et al. (2005) present a greedy algorithm to optimize the price and inventory in a multiplicative demand case.

A simpler method is proposed by Geunes et al. (2006) to solve multiple price-demand problems. Chen and Zhang (2009) prove that the profit function is concave when reference prices are dependent, regardless of whether the demand functions are additive or multiplicative in a multi-period planning horizon. They find that the price will converge and base-stock policy is optimal. Dong et al. (2009) use the Multinomial Logit model of rational consumers to study price of substitutes, but they do not consider inventory replenishment. Güler (2013) finds that if retailers ignore the impact of reference price on inventory and pricing decision, the firm's profit will suffer. Finally, Güler et al. (2014) study the impact of initial reference price on inventory and pricing decisions. A comparison of the literatures with our research is summarized in Table 1. 
Table 1. Comparison of Relevant Literature.

\begin{tabular}{|c|c|c|c|c|c|c|c|}
\hline Researcher & $\begin{array}{c}\text { Loss } \\
\text { Aversion }\end{array}$ & $\begin{array}{c}\text { Loss } \\
\text { Intensity }\end{array}$ & $\begin{array}{c}\text { Reference } \\
\text { Price }\end{array}$ & Pricing & $\begin{array}{c}\text { Supply } \\
\text { Constraint }\end{array}$ & $\begin{array}{c}\text { Inventory } \\
\text { Replenishment }\end{array}$ & Method \\
\hline Tversky, Kahneman (1991) & $\sqrt{ }$ & $\sqrt{ }$ & $\sqrt{ }$ & & & & Utility \\
\hline Hardie, Johnson and Fader (1993) & $\sqrt{ }$ & $\sqrt{ }$ & $\sqrt{ }$ & $\sqrt{ }$ & & & $\mathrm{MNL}^{*}$ \\
\hline Federgruen and Heching (1999) & & & & $\sqrt{ }$ & & $\sqrt{ }$ & $\mathrm{MDP}^{*}$ \\
\hline Barberis and Huang (2001) & $\sqrt{ }$ & $\sqrt{ }$ & & & & & Utility \\
\hline Chen and Simchi-Levi (2004) & & & & $\sqrt{ }$ & & $\sqrt{ }$ & $\mathrm{MDP}^{*}$ \\
\hline Ho and Zhang (2008) & & & $\sqrt{ }$ & $\sqrt{ }$ & & & Experiment \\
\hline Dong, Kouvelis and Tian (2009) & & & & $\sqrt{ }$ & & & $\mathrm{MNL}^{*}$ \\
\hline Ho, Lim and Cui (2010) & & & $\sqrt{ }$ & & & $\sqrt{ }$ & Utility \\
\hline Nasiry and Popescu (2011) & $\sqrt{ }$ & & $\sqrt{ }$ & $\sqrt{ }$ & & & MDP* $^{*}$ \\
\hline Kuksov and Wang (2014) & $\sqrt{ }$ & & $\sqrt{ }$ & $\sqrt{ }$ & & & $\mathrm{NE}^{*}$ \\
\hline Güler, Bilgiç and Gülllï, (2014) & & & $\sqrt{ }$ & $\sqrt{ }$ & & $\sqrt{ }$ & $\mathrm{MDP}^{*}$ \\
\hline This paper & $\sqrt{ }$ & $\sqrt{ }$ & $\sqrt{ }$ & $\sqrt{ }$ & $\sqrt{ }$ & $\sqrt{ }$ & $\begin{array}{c}\text { MDP* and } \\
\text { Utility }\end{array}$ \\
\hline
\end{tabular}

("MNL: Multinomial logit; NE: Nash equilibrium; MDP: Markov decision process)

When the reference price is lower than price, loss-averse customers may choose not to purchase a product to avoid loss, and firms may reduce prices in order to attract more customers. Price is one way to manage inventory, and a rationalized inventory provided by firms can be beneficial.

Thus, firms need to jointly consider price and inventory levels in order to maximize their profit. It is therefore necessary to examine the theoretical and practical importance of loss aversion under dynamic pricing and inventory control strategies.

\section{Dynamic Pricing and Inventory Model with Loss Aversion}

The dynamic pricing and inventory model with loss aversion model can be developed into an expert system for decision support. It is sophisticated and complex to derive, but the system is very easy to implement. Users of the expert system can obtain outputs from a set of inputs without knowing the underlying complex interactions and relationships between the inputs and outputs (see Fig.1). The proposed expert system offers expert recommendation, including replenishment quantity, pricing, inventory level, and maximal profit achievable by firms. It is an effective and efficient way to aid decision making. In particular, loss adverse customer behavior is taken into account in the expert system. Our system can streamline decision-making process, improve effectiveness, provide better customer 
service and enhance profits. In this research, the expert system can serve as a guide for firms. A firm is a decision-maker, who sets the product price and replenishes the inventory. Our goal is to maximize firm's profit over the planning horizon.

Input

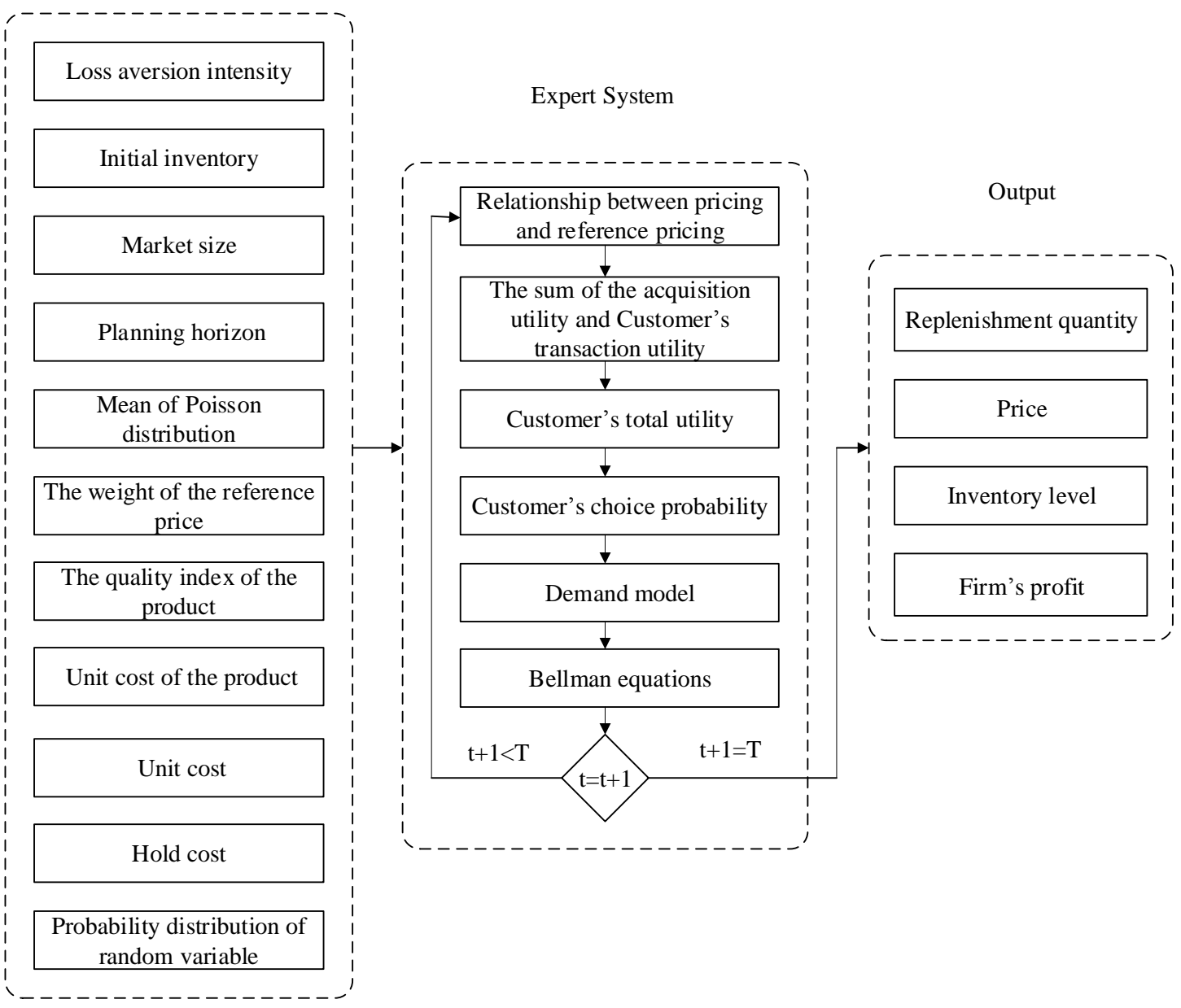

Fig. 1. The Framework of the Expert System.

Customers are not all rational (Zeldes, 1989), and many real-world phenomena cannot be explained unequivocally. However, the propensity and decision of customers to purchase affect the firm's profit. A firm therefore needs to understand customers, especially to loss-averse customers when making pricing decision. Due to inventory-holding costs, high inventory levels inflate firms' costs and reduce profits. To increase sales under high inventory pressure, a firm often lowers the price. Although a lower price increases demand, the firm's profit may suffer, as the loss of a low unit price may not be offset by its high volume. Therefore, a firm needs to jointly 
consider inventory replenishment quantity, price and customers' loss aversion intensity to optimize the system. The notations used in this research are summarized in Table 2.

Table 2

Notations Used for our Analysis

\begin{tabular}{|c|l|c|l|}
\hline $\begin{array}{c}\text { State } \\
\text { Transition }\end{array}$ & & $y_{t}\left(p_{t}\right)$ & average demand \\
\hline$t$ & time & $R_{t}$ & firm's expected revenue \\
\hline $\begin{array}{c}\text { Decision } \\
\text { Variables }\end{array}$ & & $c$ & unit cost \\
\hline$p_{t}$ & price & $b$ & backordering cost \\
\hline$x_{t}$ & $\begin{array}{l}\text { order-up-to inventory level at } \\
\text { (inventory policy) }\end{array}$ & $I_{t}$ & beginning inventory at period $t$ \\
\hline $\begin{array}{c}\text { Model } \\
\text { Parameters }\end{array}$ & & $h$ & holding cost \\
\hline$r_{t}$ & reference price & $H_{(\cdot)}$ & inventory cost \\
\hline$u\left(r_{t}\right)$ & customer's transaction utility & $z_{t}$ & variable \\
\hline$W_{t}\left(p_{t}\right)$ & customer's acquisition utility & $Q_{t}$ & order quantity \\
\hline$\eta$ & the intensity of loss aversion & $Q_{t}{ }^{*}$ & optimal order quantity \\
\hline a & quality index & $V_{t}$ & firm's expected profit \\
\hline$U_{t}$ & customer's total utility & $V_{t}{ }^{r}$ & firm's expected profit with rational \\
\hline$U_{0}$ & $\begin{array}{l}\text { customer's utility of no- } \\
\text { purchase }\end{array}$ & $\beta$ & discount factor \\
\hline$q_{t}$ & customer's choice probability & $\rho$ & bias \\
\hline$D_{t}\left(p_{t}\right)$ & demand & $C$ & maximum supply \\
\hline
\end{tabular}

\subsection{Demand Function Based on Reference-Price and Loss Aversion}

A monopolistic firm sells a single product over a finite planning horizon $t \in\{1,2, \ldots, T-1, T\}$. At the beginning of time $t$, a firm sets a selling price $p_{t}$, $p_{t} \in[\underline{p}, \bar{p}]$, where $\underline{p}$ and $\bar{p}$ are the minimum and maximum price.

The loss-averse customers arrive at the market following the Poisson distribution. Similar to Nasiry and Popescu (2011), we assume the current reference price is a convex combination of the previous price $p_{t-1}$ and the previous reference price $r_{t-1}$, and is defined as:

$$
r_{t}=\left\{\begin{array}{c}
\alpha r_{t-1}+(1-\alpha) p_{t-1}, t \in\{2, \ldots, T-1, T\} \\
p_{t}, t=1
\end{array}\right.
$$


where $\alpha$ is a weight indicating how strongly the current reference price is related to the past reference price.

A customer's transaction utility $u\left(r_{t}\right)$ is closely related to reference price $r_{t}$. To understand the loss aversion, we define a customer's transaction utility as (Schweitzer and Cachon, 2000):

$$
u\left(r_{t}\right)=\left\{\begin{array}{c}
\eta\left(r_{t}-p_{t}\right), 0<r_{t}<p_{t} \\
r_{t}-p_{t}, r_{t} \geq p_{t}
\end{array}\right.
$$

Similar to Kahneman and Tversky (1992), we assume that the loss aversion intensity $\eta$ is no less than 1 (i.e., $\eta \geq 1$ ) to capture the customers' asymmetric responses to differences from the reference price. In particular, the transaction utility function $u\left(r_{t}\right)$ in Eq. (2) indicates that customers are loss-averse, as the slope is steeper for loss than for gain. When $\eta=1$, customers are loss neutral and perceive the gain and loss with equal intensity.

For customers whose purchasing decisions depend on the current price, their acquisition utility is

$$
W_{t}\left(p_{t}\right)=a-p_{t}+\xi
$$

Thaler (1985) believes that a customer's total utility $U_{t}\left(p_{t}, r_{t}\right)$ is the sum of the acquisition utility $W_{t}\left(p_{t}\right)$ and the transaction utility $u\left(r_{t}\right)$, and can be expressed as

$$
U_{t}\left(p_{t}, r_{t}\right)=W_{t}\left(p_{t}\right)+u\left(r_{t}\right)
$$

where for loss-averse customers, $u\left(r_{t}\right) \neq 0$. When $u\left(r_{t}\right)=0$, Eq. (4) corresponds to the traditional rational decision model. The customer is likely to make a purchase (Talluri \& van Ryzin, 2004) when $U_{t}\left(p_{t}, r_{t}\right)$ is greater than 0.

Assuming customers are homogeneous, an individual customer's utility at $t$ can be expressed as $U_{t}$. We use the Multinomial Logit model to develop a customer purchase probability (Dong et al., 2009). We assume $\xi$ in Eq. (3) is double- 
exponentially distributed with mean 0 and variance $\delta^{2} \pi^{2} / 6$; and we set $\delta=1$ to standardize variance to $\operatorname{Var}(\xi)=\pi^{2} / 6$. For a given price $p_{t}$, the customer's choice probability can then be defined as

$$
\begin{gathered}
q_{t}\left(p_{t}\right)=\frac{\exp \left(U_{t}\left(p_{t}, r_{t}\right)\right)}{1+\exp \left(U_{t}\left(p_{t}, r_{t}\right)\right)} \\
\bar{q}_{t}\left(p_{t}\right)=\frac{1}{1+\exp \left(U_{t}\left(p_{t}, r_{t}\right)\right)} \\
\bar{q}_{t}\left(p_{t}\right)=1-q_{t}\left(p_{t}\right)
\end{gathered}
$$

The average demand becomes:

$$
y_{t}\left(p_{t}\right)=\Theta \cdot q_{t}\left(p_{t}\right)
$$

where $\Theta$ is the market size at time $t$ and $y_{t}\left(p_{t}\right)$ represents average demand at price $p_{t}$. An additive demand model in period $t$ can then be defined as

$$
D_{t}\left(p_{t}\right)=y_{t}\left(p_{t}\right)+\varepsilon_{t}
$$

where $\varepsilon_{t}$ is a random variable with an expected value of zero. For any $t \in\{1,2, \ldots, T-1, T\}$ and $p_{t} \in[\underline{p}, \bar{p}]$, the range of average demand $y_{t}\left(p_{t}\right)$ is $[\underline{y}(\bar{p}), \bar{y}(\underline{p})]$.

From the above, we find that demand $D_{t}\left(p_{t}\right)$ is a function of the probability of choice $q_{t}$, the market size $\Theta$ and the random variable $\varepsilon_{t}$. $D_{t}\left(p_{t}\right)$ increases with $q_{t}$ and $\Theta$.

From Eq. (5), we find that the higher the reference price $r_{t}$ is, the higher the customer's choice probability and the greater the demand are. We thus have the following theorem:

Theorem 1.: For $t \in\{1,2, \ldots, T\}$,

(1) When $p_{t} \in[\bar{p}, \underline{p}]$, demand function $D_{t}\left(p_{t}\right)$ is continuous and differentiable at 


$$
r_{t}=p_{t}
$$

(2) $D_{t}\left(p_{t}\right)$ decreases with $p_{t}$;

(3) The average demand $y_{t}\left(p_{t}\right)$ is bounded;

See the appendix for proof.

For any $p_{t}$ and $r_{t}, D_{t}\left(p_{t}\right)$ in Eq. (8) is continuous and smooth (as stated in part (1) of Theorem 1). When $p_{t} \rightarrow 0$, from Eq. (5) we find $q_{t} \rightarrow 1$, indicating that all consumers in the market would be interested in purchasing the product. Given that the market size is $\Theta$, we know that $y_{t}\left(p_{t}\right)$ is bounded by $\Theta$, as is $D_{t}\left(p_{t}\right)$.

To understand the relationship between loss aversion intensity $\eta$ and inventory policy $x_{t}$, we further explore $\eta$ and $D_{t}\left(p_{t}\right)$ in Eqs. (2) and (8), and derive the following Theorem

Theorem 2: For any $t \in\{1,2, \ldots, T\}$, demand $D_{t}\left(p_{t}\right)$ is a non-increasing function of the loss aversion intensity $\eta$.

See the appendix for proof.

When $r_{t}<p_{t}$, demand $D_{t}\left(p_{t}\right)$ is a decreasing function of $\eta$; otherwise $D_{t}\left(p_{t}\right)$ is independent of $\eta$. Theorem 2 indicates that loss aversion intensity $\eta$ has a non-positive effect on demand when $r_{t}<p_{t}$.

\subsection{Dynamic Pricing and Inventory Control Model}

At the beginning of time $t$, where $t \in\{1,2, \ldots, T\}$, a firm will review the inventory level $I_{t}$ to determine the replenishment level needed in order to meet uncertain demand $D_{t}\left(p_{t}\right)$. Without loss of generality, we assume the replenishment lead time is zero. The unmet demand is backordered, and the remaining inventory is carried over to the next period.

We develop a dynamic programming model, assuming the ordering cost is zero. 
In each period, inventory level and price are decided. We also evaluate the impacts of customers' loss aversion on profit, demand and price.

The price $p_{t}$ in Eq. (8) can be expressed as an inverse function of average demand $y_{t}$. Hence, we denote $p_{t}=p_{t}\left(y_{t}\right)$ and the expected revenue as $R_{t}\left(y_{t}\right)=y_{t} \cdot p_{t}\left(y_{t}\right)$, finite in $[\underline{y}(\bar{p}), \bar{y}(\underline{p})]$. We therefore have the following Theorem.

Theorem 3: A firm's expected revenue $R_{t}$ is a concave function of average demand $y_{t}$ at time $t$.

See the appendix for proof. The literature has extensively discussed how the actual price and reference price shape demand. Here, we propose a dynamic programming approach to optimize a retailer's inventory and pricing decisions when serving loss-averse customers.

Firm's unit cost is $c$, and the inventory cost is $H_{t}(\cdot)$ at time $t . H_{t}(\cdot)$ is continuous and convex (Chen \& Simchi-Levi, 2004a) and is positive and finite $\left(\lim _{z_{t} \rightarrow 0^{-}} H_{t}\left(z_{t}\right)=\lim _{z_{t} \rightarrow 0^{+}} H_{t}\left(z_{t}\right)=H_{t}(0)\right.$ and $\left.\lim _{z_{t} \rightarrow \pm \infty} H\left(z_{t}\right)=\infty\right)$. We therefore have

$$
H_{t}\left(z_{t}\right)=h z_{t}^{+}+b z_{t}^{-}
$$

where $z_{t}^{+}=\max \left\{z_{t}, 0\right\}$ and $z_{t}^{-}=\max \left\{0,-z_{t}\right\}$.

$V_{t}\left(I_{t}\right)$ is a firm's expected profit at time $t$ when inventory level is $I_{t}$, which is either positive or negative. Based on Markov Decision Theory and Bellman equations, we extend the model in Federgruen and Heching (1999) to address loss-averse customers and loss-neutral firm, and have

$$
V_{t}\left(I_{t}\right)=c I_{t}+\max _{I_{t} \leq x_{t} \leq I_{t}+C, y_{t} \in[\bar{y}, \underline{y}]} \Pi\left(y_{t}, x_{t}\right)
$$

where

$$
\begin{gathered}
\Pi\left(y_{t}, x_{t}\right)=y_{t} \cdot p_{t}\left(y_{t}\right)-c x_{t}-E\left[H_{t}\left(x_{t}-D_{t}\right)\right]+\beta \cdot E\left[V_{t+1}\left(x_{t}-D_{t}\right)\right] \\
\text { s.t. } \quad x_{t}=I_{t}+C, \quad t \in\{1,2, \ldots, T-1, T\}
\end{gathered}
$$




$$
\begin{aligned}
& I_{t+1}=x_{t}-D_{t}, \quad t \in\{2, \ldots, T-1, T\} \\
& V_{T+1}\left(I_{T+1}\right)=0
\end{aligned}
$$

\subsection{The Optimal Pricing and Inventory Policy with Reference Price and Loss}

Aversion

A necessary condition to solve Model (10) optimally is to ensure that it is a concave function. Through Theorem 4, we confirm that Model (10) is indeed concave and that there exists an optimal price and inventory level.

Theorem 4: For any given $t \in\{1,2, \ldots, T\}$ the following statements apply:

(1) $\Pi\left(y_{t}, x_{t}\right)$ is jointly concave in $\left(y_{t}, x_{t}\right)$;

(2) $\Pi\left(y_{t}, x_{t}\right)$ is non-increasing with $y_{t}$ and $x_{t}$;

(3) $V_{t}\left(I_{t}\right)$ is jointly concave in $\left(y_{t}, x_{t}\right)$;

(4) $V_{t}\left(I_{t}\right)$ is concave and increasing in $I_{t}$.

See the appendix for proof. Theorem 4 above did not explicitly specify the relationship between the intensity of loss aversion and the firm's profit. In the following Theorem, we examine the direct impact of loss aversion on profit.

Theorem 5: For any $t, V_{t}\left(I_{t}\right)$ is non-increasing with the loss aversion intensity $\eta$.

See the appendix for proof. Theorem 5 shows that loss aversion intensity $\eta$ is closely related to a firm's expected profit $V_{t}\left(I_{t}\right)$, threshold price $(\underline{p}$ and $\bar{p})$ and the optimal base-stock level. For any given $t$, the optimal order quantity is

$$
Q_{t}^{*}=\left\{\begin{array}{l}
Q_{t}^{*}>0, \text { if } I_{t}<x_{t}^{*} \\
Q_{t}^{*}=0, \text { if } I_{t} \geq x_{t}^{*}
\end{array}\right.
$$

Eq. (12) indicates that if the initial inventory level is less than the optimal inventory level in each period $\left(I_{t}<x_{t}^{*}\right)$, a firm must place an order with optimal order quantity $Q_{t}^{*}=x_{t}^{*}-I_{t}$. Otherwise, a firm does not place an order.

In the following, we formalize the optimal pricing and inventory policy. 
The Firm's optimal inventory level:

$$
x_{t}^{*}=\arg \max _{I_{t} \leq x_{t} \leq I_{t}+C, y \in[\underline{y}, \bar{y}]}\left\{R(y)-c x_{t}-E\left[H\left(x_{t}-y-\varepsilon_{t}\right)\right]+\beta \cdot E\left[V_{t+1}\left(x_{t}-y-\varepsilon_{t}\right)\right]\right\}
$$

where

$$
y=\frac{c \frac{\partial p(y)}{\partial y}-p(y)}{\frac{\partial p(y)}{\partial y}}
$$

Eq. (13) shows that it is optimal to order up to $x_{t}^{*}$ at $t$. The firm's expected profit is maximized over the planning horizon. From Eq. (13), we can derive the optimal price next.

The demand can be expressed as a function of optimal inventory level:

$$
y_{t}^{*}\left(x_{t}\right)=\arg \max _{I_{t} \leq x_{t} \leq I_{t}+C, y_{t} \in[\bar{y}, \underline{y}]}\left\{R\left(y_{t}\right)-E\left[H\left(x_{t}-y_{t}-\varepsilon_{t}\right)\right]+\beta \cdot E\left[V_{t+1}\left(x_{t}-y_{t}-\varepsilon_{t}\right)\right]\right\}
$$

By taking the inverse function of average demand $y_{t}$ above, we find the optimal price:

$$
p_{t}^{*}\left(x_{t}\right)=p_{t}\left(y_{t}^{*}\left(x_{t}\right)\right)
$$

\section{Numerical Study}

In this section, we provide numerical examples to examine the effects of loss aversion on pricing, inventory level, demand and profit to validate the proposed model and to derive managerial implications.

The planning horizon has $T=9$. We assume that customers demand follows a Poisson distribution with mean $\Theta=50$; the initial inventory is $I_{0}=40$, the weight of the reference price is $\alpha=0.8$, and the quality of the product is $a=11.75$. The unit cost of the product is $c=2$; the manufacturer's supply capacity per period is limited to $C=10$, and the inventory cost per period is $H_{t}\left(z_{t}\right)=h z_{t}^{+}+b z_{t}^{-}$with $h=1$ and $b=4$. The demand is $D_{t}\left(p_{t}\right)=\Theta_{t} \cdot q_{t}\left(p_{t}\right)+\varepsilon_{t}$, and $P\{\varepsilon=1\}=P\{\varepsilon=-1\}=0.5$. 


\subsection{The Impact of Price and Inventory on Profit Under Loss Aversion}

To understand the relationships between expected profit, inventory, demand and price, we set $\eta=2.25$, which is empirically proved by Tversky and Kahneman (1992) to describe the effects of reference price in real life. For each time period, the beginning inventory varies at a decrement of 5: $I_{0}=\{60,55,50,45,40,35,30\}$; so does the demand: $D_{1}=\{45,40,35,30,25,20,15\}$.

As the inventory level affects the customer service level (i.e., the demand that can be satisfied), inventory plays an important role in price setting and profit. Based on Eqs. (13) and (14), we find that inventory and price are negatively correlated, such that high inventory corresponds to low price (Fig. 2(a)). Thus, we numerically prove that the optimal price exists given the initial inventory level, and Theorem 4 is validated. We are able to identify the impact of inventory on demand (see Fig. 2(b)) and derive the price.

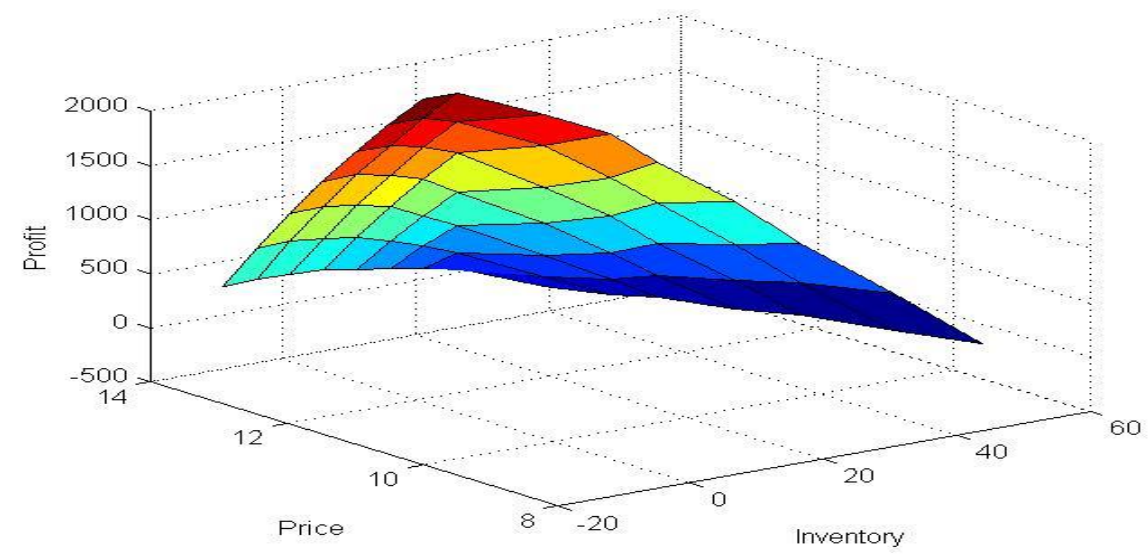

(a) Inventory level affects firm's price decision, which affects profits 


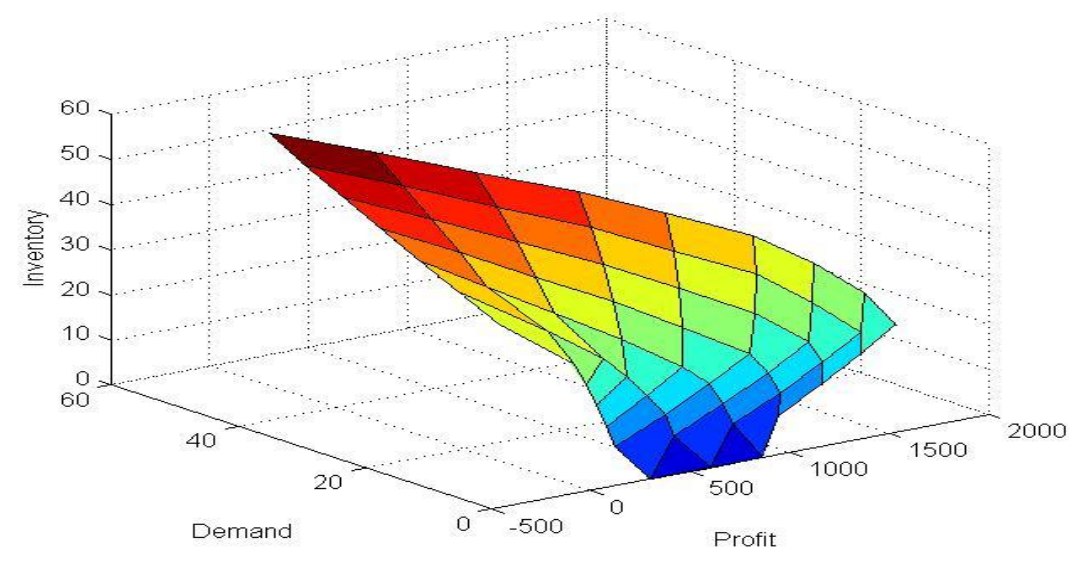

(b) Inventory level affects the demand satisfied, which affects profits

Fig. 2. The Impacts of Inventory on Price, Demand and Profits

To show that demand is a decreasing function of loss aversion intensity, we set $p=8.25$ and $r=6.5$. We obtain Fig. 3, which validates Theorem 2. We find that when $\eta$ is large, demand asymptotically decreases to zero. When the loss aversion intensity reaches a certain extent, customers will not buy products.

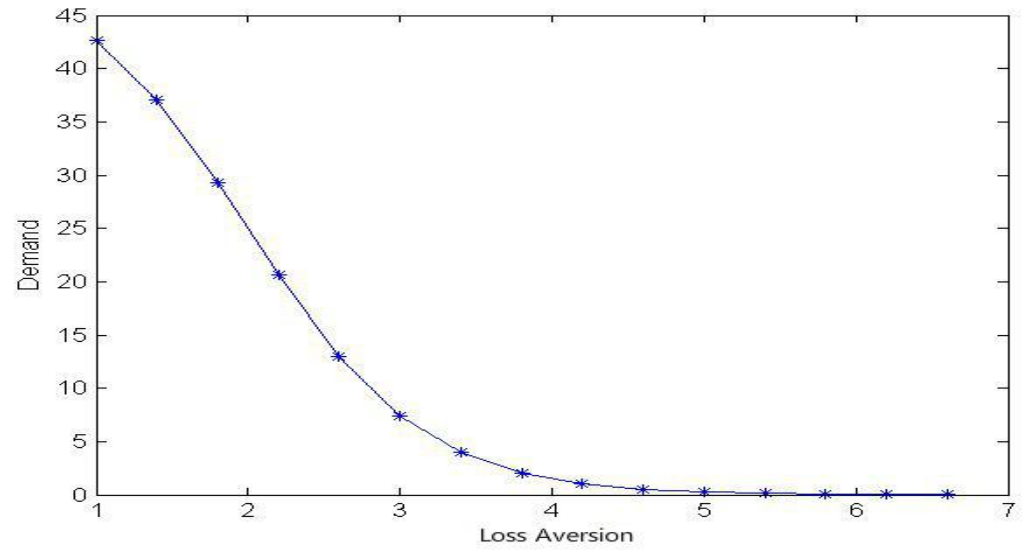

Fig. 3. The Impact of Loss Aversion on Demand

In Fig. 2(b), for $r=6.5$ and $\eta=2.25$, we find the optimal inventory levels are 5, 26, and 40, respectively, corresponding to $I_{0}$ at $(30,50,70)$ and $D_{1}$ at $(15,35,45)$. Their respective prices are 7.2,8.1, and 8.8. Fig. 4 shows that high inventory level 
corresponds to low price, which results in higher demand.

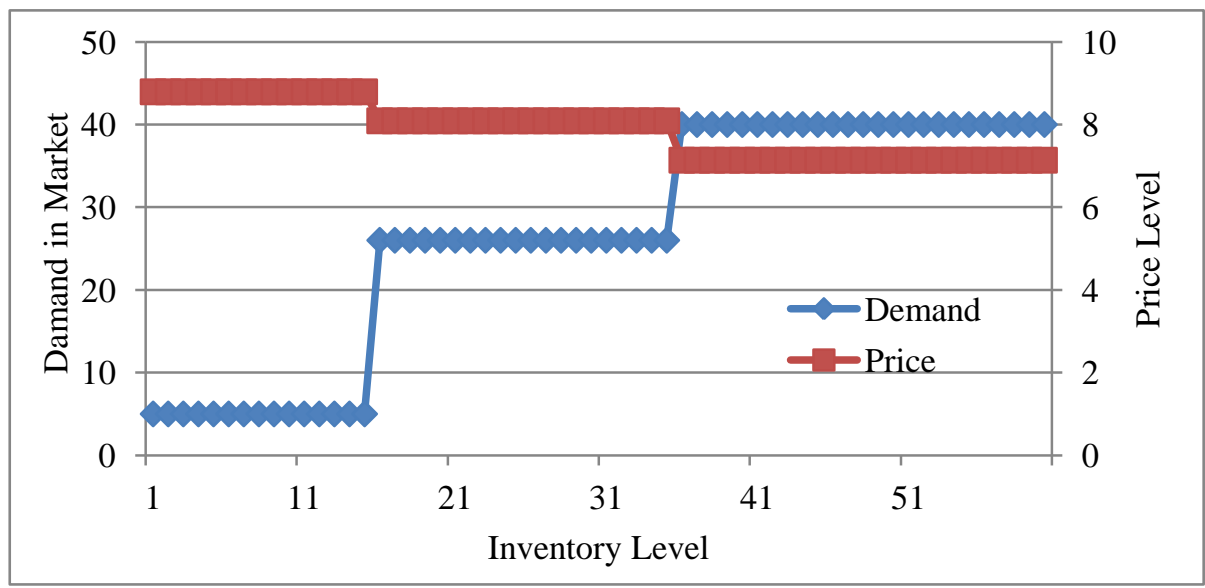

Fig. 4. The Impact of Inventory Level on Demand and Price

We use Fig. 5 to illustrate the impact of loss aversion intensity on price and inventory levels. When inventory level is 5, 26, and 40 and the loss aversion intensity $\eta$ is set at 1.75, 2.25 and 2.75, the corresponding price is determined as shown in Fig. 5. We find that loss aversion is positively associated with product price, which is consistent with the findngs of Heidhues and Köszegi (2008). Fig. 5 shows that optimal price converges monotonically to a steady-state price at a higher inventory level.

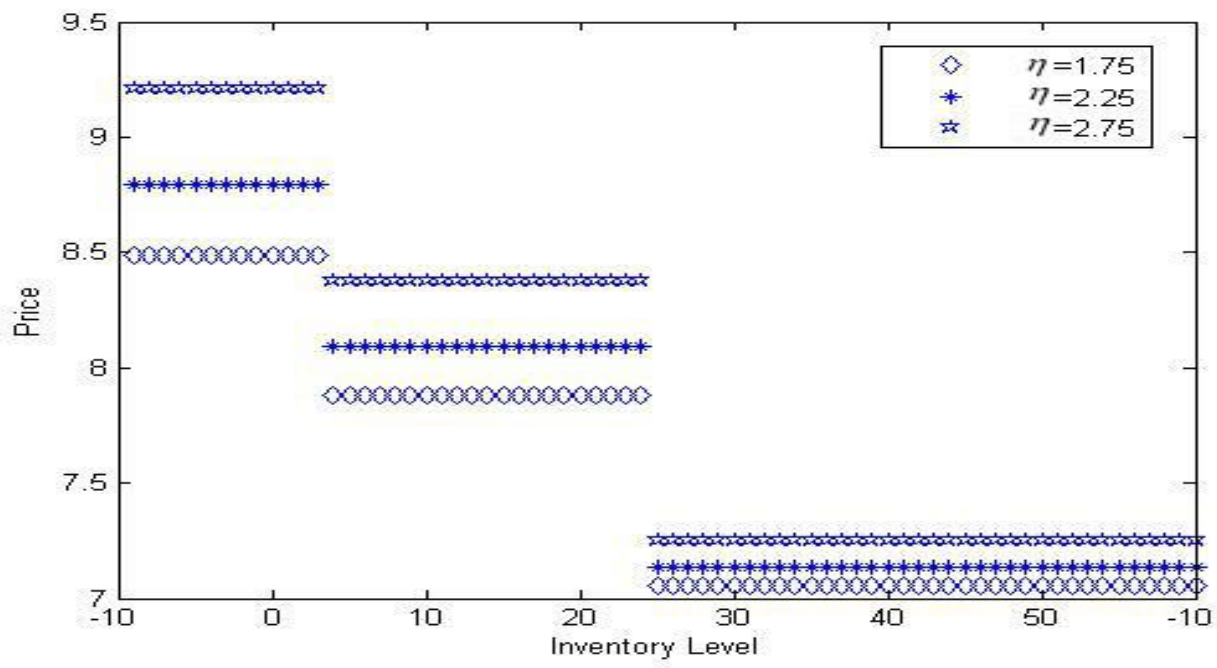

Fig. 5. The Impact of Loss Aversion Intensity on Price and Inventory Levels 
Fig. 6 shows the relationship between loss aversion and profit, when $r=6.5$ and $p=8.25$. Consistent with Theorem 5 , we find that high loss aversion intensity corresponds to low profit.

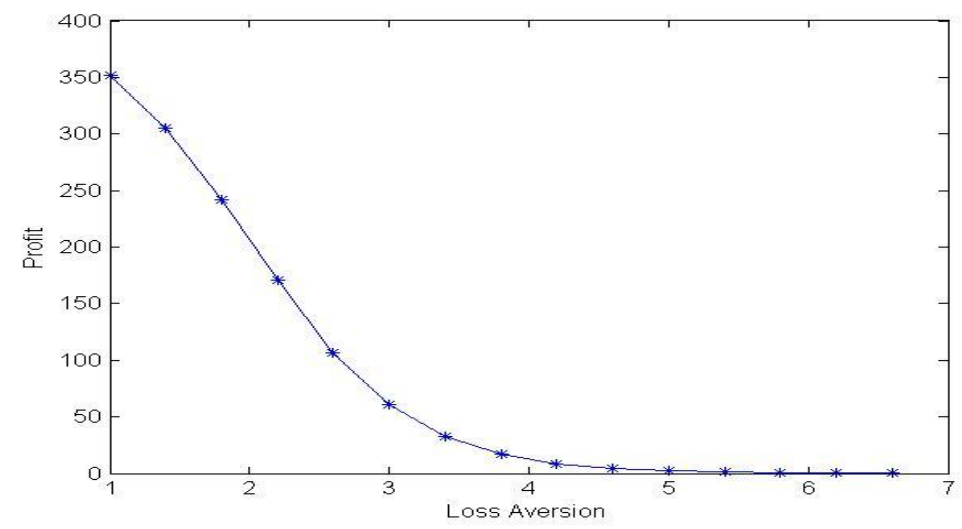

Fig. 6. Profit and Loss Aversion Intensity

\subsection{The Impacts of Customer Loss Aversion and Reference Price}

Although it is of practical importance to jointly consider inventory level and price, it is difficult to determine both simultaneously when facing loss-averse customers, due to two reasons: (i) we are addressing a multi-period dynamic pricing issue, and (ii) loss aversion affects both price and inventory decisions. We have theoretically established the impact of reference price on customer choice in Eqs. (1), (2) and (5). To understand the significance of our model, which incorporates loss aversion and reference price in the decision model, we compare its profit performance with that of the rational-customer model.

We define $V_{t}^{f}$ as the firm's profit when customers are loss neutral. The following equation examines the difference:

$$
\rho=\frac{\left|V_{t}-V_{t}^{f}\right|}{V_{t}^{f}} * 100 \%
$$

Customers' loss aversion negatively affects the firm's expected profit. In this subsection, we assume $p_{t}=8.25$. Fig. 7(a) shows that at $\eta \in[1,1.5]$, the intensity of 
loss aversion is positively associated with profit improvement rate. When the loss aversion intensity is high (e.g., $\eta=1.5$ ), if the firm does not consider $\eta$, their profit will be greatly compromised (reduced by $36 \%$ ).

Fig. 7(b) shows that the improvement rate increases with reference price in the range of $r_{t} \in[8.25,11.75]$. When the reference price is at $r_{t}=11.25$ (greater than $\left.p_{t}=8.25\right)$, the firm's profit increases by $2.75 \%$ if the reference price is taken into account in optimizing price and inventory decisions.
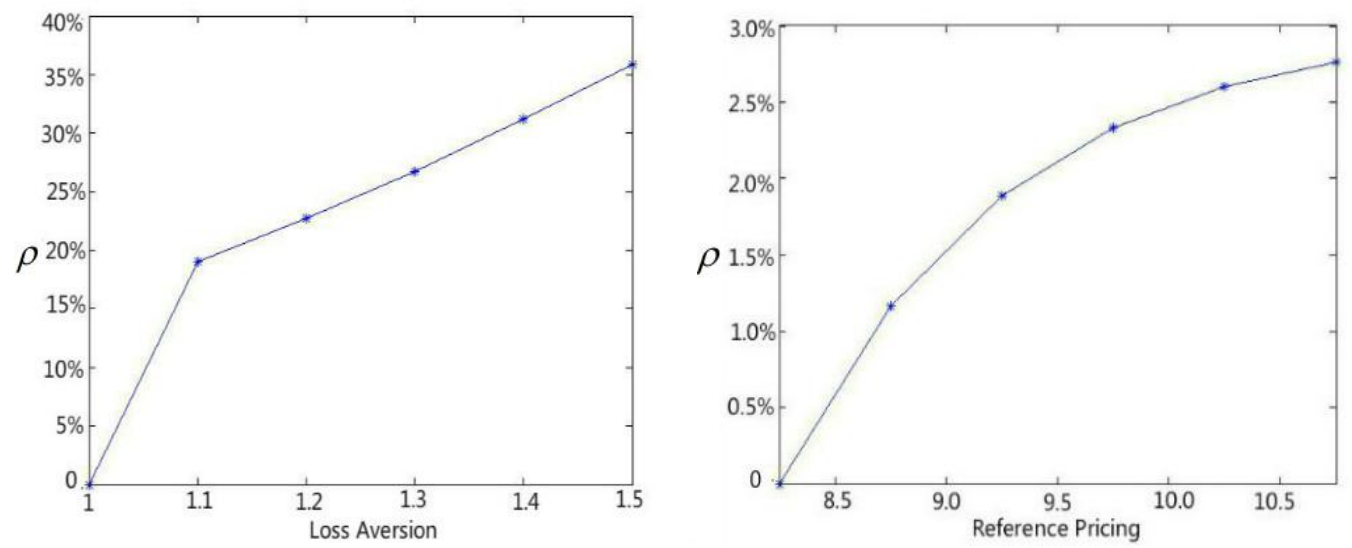

(a) The impact of reference price when $r_{t}<p_{\mathrm{t}}$; (b) The impact of reference price when $r_{t}>p_{t}$

Fig. 7. Contrast of Profit Improvements between Loss-Aversion Model and Rational Model

Retailers need to take consumers' loss aversion behavior into consideration when making price change. Customers will shy away from the product if its previous price was significantly lower and the customers have high loss-averse intensity. Namely, customers' perception of high-loss will drive them away and prevent them from purchase. Firms need to systematically and conscientiously manage their price and inventory by understanding customers risk attitude and intensity, so as to outperform their competitors and derive higher profits.

\section{Conclusions and Future Research}

\subsection{Conclusions}


Our results throw new light on pricing and inventory management by incorporating customer behavior and reference price in a multi-period system. We offer an analytical model to maximize firm's profit and show the optimal inventory level, replenishment quantity and corresponding price. Numerical examples are used to illustrate and validate the model and to derive managerial insights. To demonstrate the practicability of our models, we show how a dynamic programming model yields good results when facing customer loss aversion under realistic scenario. Results in this paper help improve the quality of policy maker's decision.

The differences of our research and the literature are threefold. First, we use Multinomial Logit model to determine the purchase probability of a customer, by taking into account customers' loss aversion behavior. Based on the results of Multinomial Logit model, we define the demand as a function of purchase probability and market size. Second, based on the demand function, we develop a dynamic programming model, which uses Markov Decision Theory and Bellman equations, to address pricing and inventory control issues. The dynamic programming solution tactic is incorporated in the expert system framework to build the Intelligent Management System. Our model shows managers the benefits of considering consumers' behavior through multiple periods. Finally, we provide proofs for all theorems and optimal solutions developed in this research. By incorporating the consumer's aversion behavior in the expert system, we more realistically reflect the true business environment and help managers make better decisions and generate higher profits.5.2 Future Research

In this research, we made several assumptions about the model, as they are relevant and important in modeling customers' loss-averse behavior. In terms of weaknesses, this study has some limitations. First, we focus on loss-averse consumer behavior rather than a combination of consumers' and decision-maker's behavior. Second, one retailer does not represent all markets. To develop a comprehensive view, it is important to include market competition. Researchers who are interested in applying the behavioral decision theory to the choice model and to study the 
marketing campaign and promotion strategy can use our model as a foundation for further study. Examples of future research may include the following:

(1) Comparing homogeneous customers with heterogeneous customers to examine the impacts of a firm's optimal pricing and inventory decisions on firm performance.

(2) Determining how to identify the optimal price and determine the inventory level when facing loss-averse customers in a competitive environment.

(3) Determining how to optimize pricing and inventory decisions when both firms and their customers are loss-averse in a multi-period planning horizon.

\section{Acknowledge}

This research was partially supported by the support from the National Science Foundation of China Grants Nos. 71432002, 71272058 and 71172172, International Graduate Exchange Program of Beijing Institute of Technology. 


\section{Appendix}

\section{Proof of Theorem 1.}

(1) Due to its simplicity, we omitted here.

(2) We consider two cases: $r_{t} \geq p_{t}$ and $r_{t}<p_{t}$. Taking the first-order derivative

$$
\frac{d D_{t}}{d p_{t}}=\left\{\begin{array}{c}
\Theta \cdot \frac{(-1-\eta) \cdot \exp \left(a-p_{t}+\eta\left(r_{t}-p_{t}\right)\right)}{\left(1+\exp \left(a-p_{t}+\eta\left(r_{t}-p_{t}\right)\right)\right)^{2}}, r_{t}<p_{t} \\
\Theta \cdot \frac{-2 \exp \left(a-p_{t}+\left(r_{t}-p_{t}\right)\right)}{\left(1+\exp \left(a-p_{t}+\left(r_{t}-p_{t}\right)\right)\right)^{2}}, r_{t} \geq p_{t}
\end{array}\right.
$$

we conclude that $\frac{d D_{t}}{d p_{t}}<0$

(3) For $p_{t} \in[\bar{p}, \underline{p}]$, based on Eq. (5) we have $q_{t} \in[0,1]$. Similarly, from Eq. (8), we find $y_{t}\left(p_{t}\right) \in\left[0, \Theta_{t}\right]$. Thus, the average demand $y_{t}\left(p_{t}\right)$ is bounded.

To show that demand is a concave function of price, we combine (1)-(2) in Theorem 1 and find

$$
\begin{aligned}
& \frac{d^{2} D_{t}}{d^{2} p_{t}}=\left\{\begin{array}{c}
\Theta(-1-\eta)^{2} \cdot \frac{\exp \left(a-p_{t}+\eta\left(r_{t}-p_{t}\right)\right)\left(1-\exp \left(a-p_{t}+\eta\left(r_{t}-p_{t}\right)\right)\right)}{\left(1+\exp \left(a-p_{t}+\eta\left(r_{t}-p_{t}\right)\right)\right)^{3}}, r_{t}<p_{t} \\
4 \Theta \cdot \frac{\exp \left(a-p_{t}+\left(r_{t}-p_{t}\right)\right)\left(1-\exp \left(a-p_{t}+\left(r_{t}-p_{t}\right)\right)\right)}{\left(1+\exp \left(a-p_{t}+\left(r_{t}-p_{t}\right)\right)\right)^{3}}, r_{t} \geq p_{t}
\end{array},\right. \\
& \frac{d^{2} D_{t}}{d^{2} p_{t}}<0
\end{aligned}
$$

when $\left(a-p_{t}+\eta\left(r_{t}-p_{t}\right)\right)$ is positive, the customer is incentivized to buy. Demand function $D_{t}\left(p_{t}\right)$ is concave on the second-order of price $p_{t}$, so there exists a maximum number of demand $D_{t}\left(p_{t}\right)$ over $[\bar{p}, \underline{p}]$. This ends the proof. 


\section{Proof Theorem 2.}

Based on the monotonicity property of demand function, we examine the effect of loss aversion on demand.

(i) When $r_{t}<p_{t}$, we have

$$
\frac{d D_{t}}{d \eta}=\frac{\Theta\left(r_{t}-p_{t}\right) \exp \left(a-p_{t}+\eta\left(r_{t}-p_{t}\right)\right)}{\left[1+\exp \left(a-p_{t}+\eta\left(r_{t}-p_{t}\right)\right)\right]^{2}}<0,
$$

(ii) When $r_{t} \geq p_{t}$, we have

$$
\frac{d D_{t}}{d \eta}=0
$$

This ends the proof.

\section{Proof of Theorem 3.}

(i) When $r_{t}<p_{t}$, taking the first-order derivative of $R_{t}\left(y_{t}\right)=y_{t} \cdot p_{t}\left(y_{t}\right)$ on $y_{t}$, we have

$$
1=\Theta \frac{\left(\exp \left(a-p_{t}+\eta\left(r_{t}-p_{t}\right)\right)\right)(-1-\eta)\left(1+\exp \left(a-p_{t}+\eta\left(r_{t}-p_{t}\right)\right)\right) \frac{d p_{t}}{d y_{t}}-\left(\exp \left(a-p_{t}+\eta\left(r_{t}-p_{t}\right)\right)\right)^{2}(-1-\eta) \frac{d p_{t}}{d y_{t}}}{\left(1+\exp \left(a-p_{t}+\eta\left(r_{t}-p_{t}\right)\right)\right)^{2}},
$$

then

$$
\frac{d p_{t}}{d y_{t}}=\frac{\left[1+\exp \left(a-p_{t}+\eta\left(r_{t}-p_{t}\right)\right)\right]^{2}}{\Theta(-1-\eta) \exp \left(a-p_{t}+\eta\left(r_{t}-p_{t}\right)\right)}
$$

The second derivative of $R_{t}\left(y_{t}\right)=y_{t} \cdot p_{t}\left(y_{t}\right)$ becomes

$$
\frac{d^{2} p_{t}}{d y_{t}{ }^{2}}=\frac{\left[\exp \left(a-p_{t}+\eta\left(r_{t}-p_{t}\right)\right)-1\right]\left[1+\exp \left(a-p_{t}+\eta\left(r_{t}-p_{t}\right)\right)\right]^{3}}{(-1-\eta)\left[\Theta \exp \left(a-p_{t}+\eta\left(r_{t}-p_{t}\right)\right)\right]^{2}}
$$

We then have

$$
\frac{d^{2} R_{t}}{d y_{t}^{2}}=2 \frac{d p_{t}}{d y_{t}}+y_{t} \frac{d^{2} p_{t}}{d y_{t}^{2}}
$$




$$
\begin{aligned}
& =\frac{\left[1+\mathrm{ex}\left(\mathrm{p}-p_{t}+\eta\left(\begin{array}{ll}
r- & \phi)
\end{array}\right)\right]^{2}\right.}{\Theta(-1-\eta) \operatorname{ex}\left(p-p_{t}+\eta\left(\begin{array}{ll}
r- & \phi
\end{array}\right)\right.} \cdot\left[1+\mathrm{ex}\left(\mathrm{p}-p_{t}+\eta\left(\begin{array}{ll}
r-\not)
\end{array}\right)\right]\right. \\
& <0
\end{aligned}
$$

(ii) When $r_{t} \geq p_{t}$, we have

$$
\begin{aligned}
& \frac{d^{2} R_{t}}{d y_{t}^{2}}=2 \frac{d p_{t}}{d y_{t}}+d_{t} \frac{d^{2} p_{t}}{d y_{t}^{2}} \\
& =\frac{\left[1+\exp \left(a-p_{t}+\left(r_{t}-p_{t}\right)\right)\right]^{2}}{-2 \Theta \exp \left(a-p_{t}+\left(r_{t}-p_{t}\right)\right)} \cdot\left[1+\exp \left(a-p_{t}+\left(r_{t}-p_{t}\right)\right)\right]<0
\end{aligned}
$$

Based on (i) and (ii), we conclude that $\frac{d^{2} R_{t}}{d y_{t}{ }^{2}}<0$, and the optimal expected revenue exists.

This ends the proof.

\section{Proof Theorem 4.}

$>\quad$ Part (1)

From Eq. (11), we have

$$
\Pi\left(y_{t}, x_{t}\right)=R_{t}\left(y_{t}\right)-c x_{t}-E H_{t}\left(x_{t}-y_{t}-\varepsilon_{t}\right)+\beta \cdot E V_{t+1}\left(x_{t}-y_{t}-\varepsilon_{t}\right)
$$

Let $g\left(y_{t}, x_{t}\right)=R_{t}\left(y_{t}\right)-E H\left(x_{t}-y_{t}-\varepsilon_{t}\right)+\beta \cdot E V_{t+1}\left(x_{t}-y_{t}-\varepsilon_{t}\right)$

and $R_{t}\left(y_{t}\right)=p_{t}\left(y_{t}\right) \cdot y_{t}$. Then, $R_{t}\left(y_{t}\right)$ is concave in $y_{t}$ and $-H_{t}\left(x_{t}-y_{t}-\varepsilon_{t}\right)$ is concave in $x_{t}$ (Theorem 3$)$.

In the following, we use the inductive approach to prove that $g\left(y_{t}, x_{t}\right)$ is concave.

(i) For $r_{t} \geq p_{t}$ and define $y_{t}^{1}$ and $y_{t}^{2}$ as two different demand quantities; while $x_{t}^{1}$, and $x_{t}^{2}$ as different inventory levels. Plugging them into Eq. (A1), we find

(a) If $t=1$, then 


$$
g\left(\frac{y_{1}^{1}+y_{1}^{2}}{2}, \frac{x_{1}^{1}+x_{1}^{2}}{2}\right)<\frac{1}{2} g\left(y_{1}^{1}, x_{1}^{1}\right)+\frac{1}{2} g\left(y_{1}^{2}, x_{1}^{2}\right)
$$

(b) For $t \geqslant 2$, we assume that

$$
\begin{aligned}
& g\left(\frac{y_{t-1}^{1}+y_{t-1}^{2}}{2}, \frac{x_{t-1}^{1}+x_{t-1}^{2}}{2}\right)<\frac{1}{2} g\left(y_{t-1}^{1}, x_{t-1}^{1}\right)+\frac{1}{2} g\left(y_{t-1}^{2}, x_{t-1}^{2}\right) \text { is true, } \\
& \text { we have } g\left(\frac{y_{t}^{1}+y_{t}^{2}}{2}, \frac{x_{t}^{1}+x_{t}^{2}}{2}\right)<\frac{1}{2} g\left(y_{t}^{1}, x_{t}^{1}\right)+\frac{1}{2} g\left(y_{t}^{2}, x_{t}^{2}\right) .
\end{aligned}
$$

(ii) When $r_{t}<p_{t}, g\left(\frac{y_{t}^{1}+p_{t}^{2}}{2}, \frac{y_{t}^{1}+x_{t}^{2}}{2}\right)<\frac{1}{2} g\left(y_{t}^{1}, x_{t}^{1}\right)+\frac{1}{2} g\left(y_{t}^{2}, x_{t}^{2}\right)$ is true.

Therefore, $g\left(y_{t}, x_{t}\right)$ is concave at $y_{t}$ and $x_{t} \cdot \Pi\left(y_{t}, x_{t}\right)$ is concave at $y_{t}$ and $x_{t}$ with $p_{t}<c . \Pi\left(y_{t}, x_{t}\right)$ is non-increasing at $y_{t}$ and $x_{t}$ by induction.

\section{$>\quad$ Part (2)}

$V_{t}\left(x_{t}\right)$ is concave in $y_{t}$ and $x_{t}$ as proved in Part (1).

\section{$\underline{\text { Part (3) }}$}

For any given $t$, we have $V_{t}\left(I_{t}\right)=V_{t}\left(x_{t}-y_{t}-\varepsilon_{t}\right)$ as shown Eq. (10).

Therefore, $V_{t}\left(I_{t}\right)$ is non-increasing at $I_{t}$.

This ends the proof.

\section{Proof of Theorem 5.}

(i) When $r_{t} \geq p_{t}$, we have $\frac{d V_{t}}{d \eta}=0$.

(ii) When $r_{t}<p_{t}$, we have $\frac{d V_{t}}{d \eta}=p_{t} \frac{d y_{t}}{d \eta}+h \frac{d y_{t}}{d \eta}=\left(p_{t}+h\right) \frac{d y_{t}}{d \eta}$ 


$$
=\left(p_{t}+h\right) \frac{\Theta\left(r_{t}-p_{t}\right) \exp \left(a-p_{t}+\eta\left(r_{t}-p_{t}\right)\right)}{\left[1+\exp \left(a-p_{t}+\eta\left(r_{t}-p_{t}\right)\right)\right]^{2}}<0
$$

Thus, $V_{t}\left(I_{t}\right)$ is non-increasing at $\eta$, for any $r_{t}$ and $p_{t}$.

This ends the proof. 


\section{References}

Barberis, N., \& Huang, M. (2001). Mental accounting, loss aversion, and individual stock returns. The Journal of Finance, 56, 1247-1292.

Biller, S., Chan, L. M. A., Simchi-Levi, D., \& Swann, J. (2005). Dynamic pricing and the direct-to-customer model in the automotive industry. Electronic Commerce Research, 5, 309-334.

Chen, X., \& Zhang, J. (2009). A stochastic programming duality approach to inventory centralization games. Operations Research, 57, 840-851.

Chen, X., \& Simchi-Levi, D. (2004a). Coordinating inventory control and pricing strategies with random demand and fixed ordering cost: The finite horizon case. Operations Research, 52, 887-896.

De Giorgi, E. G., \& Post, T. (2011). Loss aversion with a state-dependent reference point. Management Science, 57, 1094-1110.

Dong, L., Kouvelis, P., \& Tian, Z. (2009). Dynamic pricing and inventory control of substitute products. Manufacturing \& Service Operations Management, 11, 317-339.

Federgruen, A., \& Heching, A. (1999). Combined pricing and inventory control under uncertainty. Operations Research, 47, 454-475.

Federgruen, A., \& Heching, A. (2002). Multilocation combined pricing and inventory control. Manufacturing \& Service Operations Management, 4, 275-295.

Geunes, J., Romeijn, H. E., \& Taaffe, K. (2006). Requirements planning with pricing and order selection flexibility. Operations Research, 54, 394-401.

Güler, M. G. (2013). The value of modeling with reference effects in stochastic inventory and pricing problems. Expert Systems with Applications, 40, 6593-6600.

Güler, M. G., Bilgiç, T., \& Güllü, R. (2014). Joint inventory and pricing decisions with reference effects. IIE Transactions, 46, 330-343.

Hardie, B. G., Johnson, E. J., \& Fader, P. S. (1993). Modeling loss aversion and reference dependence effects on brand choice. Marketing science, 12, 378-394.

Heidhues, P., \& Köszegi, B. (2008). Competition and price variation when consumers are loss averse. The American Economic Review, 98, 1245-1268.

Ho, T. H., Lim, N., \& Cui, T. H. (2010). Reference dependence in multilocation newsvendor models: A structural analysis. Management Science, 56, 1891-1910.

Ho, T. H., \& Zhang, J. (2008). Designing pricing contracts for boundedly rational customers: Does the framing of the fixed fee matter?. Management Science, 54, 686-700.

Kahneman, D., \& Tversky, A. (1979). Prospect theory: An analysis of decision under risk. Econometrica: Journal of the Econometric Society, 47, 263-291.

Kuksov, D., \& Wang, K. (2014). The bright side of loss aversion in dynamic and competitive markets. Marketing Science, 33, 693-711.

Liu, S. C., \& Chen, J. R. (2011). A heuristic method for the inventory routing and pricing problem in a supply chain. Expert Systems with Applications, 38, 1447-1456. 
Markowitz, H. (1952). Portfolio selection. The Journal of Finance, 7, 77-91.

Mazumdar, T., Raj, S. P., \& Sinha, I. (2005). Reference price research: Review and propositions. Journal of Marketing, 69, 84-102.

Mutikani, L. (2015). U.S. existing home sales at nine-month low, supply limited, http://www.reuters.com/article/2015/02/23/us-usa-economy-housing-idUSKBNOL R1DE20150223.

Nasiry, J., \& Popescu, I. (2011). Dynamic pricing with loss-averse consumers and peak-end anchoring. Operations Research, 59, 1361-1368.

Petruzzi, N. C., \& Dada, M. (1999). Pricing and the newsvendor problem: A review with extensions. Operations Research, 47, 183-194.

Pope, D. G., \& Schweitzer, M. E. (2011). Is Tiger Woods loss averse? Persistent bias in the face of experience, competition, and high stakes. The American Economic Review, 101, 129-157.

Popescu, I., \& Wu, Y. (2007). Dynamic pricing strategies with reference effects. Operations Research, 55, 413-429.

Schwartz, T. (1970). On the possibility of rational policy evaluation. Theory and Decision, 1, 89-106.

Schweitzer, M. E., \& Cachon, G. P. (2000). Decision bias in the newsvendor problem with a known demand distribution: Experimental evidence. Management Science, 46, 404-420.

Talluri, K., \& Van Ryzin, G. (2004). Revenue management under a general discrete choice model of consumer behavior. Management Science, 50, 15-33.

Thaler, R. (1985). Mental accounting and consumer choice. Marketing science, 4 , 199-214.

Thaler, R. H., Tversky, A., Kahneman, D., \& Schwartz, A. (1997). The effect of myopia and loss aversion on risk taking: An experimental test. The Quarterly Journal of Economics, 112, 647-661.

Tversky, A., \& Kahneman, D. (1991). Loss aversion in riskless choice: A reference-dependent model. The Quarterly Journal of Economics, 106, 1039-1061.

Tversky, A., \& Kahneman, D. (1992). Advances in prospect theory: Cumulative representation of uncertainty. Journal of Risk and Uncertainty, 5, 297-323.

Wagner, H. M., \& Whitin, T. M. (1958). Dynamic version of the economic lot size model. Management Science, 5, 89-96.

Zeldes, S. P. (1989). Optimal consumption with stochastic income: Deviations from certainty equivalence. The Quarterly Journal of Economics, 104, 275-298. 